\title{
A Comparison of Oral Health Related Knowledge between Undergraduate Medical and Dental Students
}

\author{
Bokhari SAH ${ }^{1 *}$, Bello SM², Sanikommu S', Hamza \\ $\mathbf{S A}^{3}$ and Alotaibi $\mathbf{A M}^{4}$ \\ ${ }^{1}$ Department of Dental Public Health, College of \\ Dentistry, King Faisal University, Kingdom of Saudi Arab \\ ${ }^{2}$ Department of Biomedical Sciences, College of Dentistry, \\ King Faisal University, Saudi Arabia \\ ${ }^{3}$ University of Faisalabad, College of Dentistry, Pakistan \\ ${ }^{4}$ Department of Periodontology, College of Dentistry, \\ King Faisal University, Saudi Arabia \\ *Corresponding author: Syed Akhtar Hussain \\ Bokhari, Department of Dental Public Health, College of \\ Dentistry, King Faisal University, Al-hofuf 31972, Saudi \\ Arabia
}

Received: March 01, 2021; Accepted: March 25, 2021; Published: April 01, 2021

\begin{abstract}
Aim: Studies have reported that the knowledge of medical doctors about dental conditions is not satisfactory. Medical and dental students need to have and reflect good oral health knowledge as they will be major providers of health services in future. This study was conducted to assess and compare the level of oral health knowledge of medical and dental students.
\end{abstract}

Materials and Methods: Using a self-administered structured questionnaire, cross-sectional study was conducted at King Faisal University University, Saudi Arabia. The survey tool consisting of 25 items assessed knowledge about oral health problems, etiology and importance in relation to general health. Descriptive statistics were performed using SPSS version 20.

Results: Medical students exhibited a good level of oral health knowledge on $16(64 \%)$ items, whereas dental students demonstrated on 18 items (72\%) $(p=0.02)$. In both streams, male students displayed a good level of knowledge on 17 items, while female displayed on 11 items. Mean score of male students to all the questions was $80.68 \%$ and that of females was $66.96 \%(p=0.001)$. Dental students scored marginally better than medical students for 14 out of 25 items, and mean scores was insignificant between medical and dental students $(p=0.21)$. Students of years 2,3 and 4 displayed better knowledge compared to those from years 1 and $5(p=0.001)$. Students from any particular year did not seem to be having consistently better knowledge than the other years across all the items.

Conclusion: This study showed a moderate to good level of knowledge about oral health. Dental students and men displayed somewhat better knowledge levels compared to medical students and women, respectively.

Clinical Significance: This study highlights the importance of scientific oral health knowledge for the future health care professionals. Objective is to draw attention towards incorporation of preventive oral health sciences in medical curriculum at undergraduate level.

Keywords: Oral Health; Knowledge; Medical; Dental; Students

\section{Introduction}

Oral health is an essential component and prerequisite for the overall health of a person. It is therefore important for both medical and dental students to have and reflect good oral health knowledge as they will be major providers of health services in future [1]. Usually, most of the patients including those with complaints in the orofacial region, make their first contact with a general medical practitioner [2]. Physicians offer a range of healthcare services to the patients suffering from dental problems. The services include emergency care, screening and referral. Medical professionals receive little training in addressing oral health issues during their educational programs or elsewhere; thus they display low levels of oral health knowledge and low levels of confidence in its applications [3,4]. Various studies reported that the knowledge of medical doctors about dental conditions was not satisfactory [5]. Medical schools' curriculum was found to be inadequately covering diagnosis and management of oral disease. This concept is confirmed by a study, where fifty-four per cent of the physicians agreed that problems of teeth and gums could affect pregnancy outcomes, but in their routine practice, they failed to counsel their patients to seek dental care during pregnancy [6]. Fifty per cent dentists and physicians believed that diabetic patients are at a greater risk for tooth loss because of periodontal disease [7] and $48.4 \%$ medical interns never screened patients of periodontal illness [8]. In a study by Rabiei et al. [9] physicians agreed to know about oral health care and were willing to include preventive oral health services to their routine practice. Medical students also showed poor to moderate knowledge in medical problems in dentistry [10] and a recent study from India reported poor oral health awareness by undergraduate medical students [11].

The current curriculum of medical schools is either deficient or non-existent concerning oral health [12]. Inadequate coverage of dental content in the medical curriculum compromises the basic dental knowledge of medical graduates and impedes their confidence in offering basic oral health advice [13].

Significance of providing some dental knowledge to the medical professionals has been widely acknowledged [14] as basic knowledge 
Table 1: Study Questionnaire.

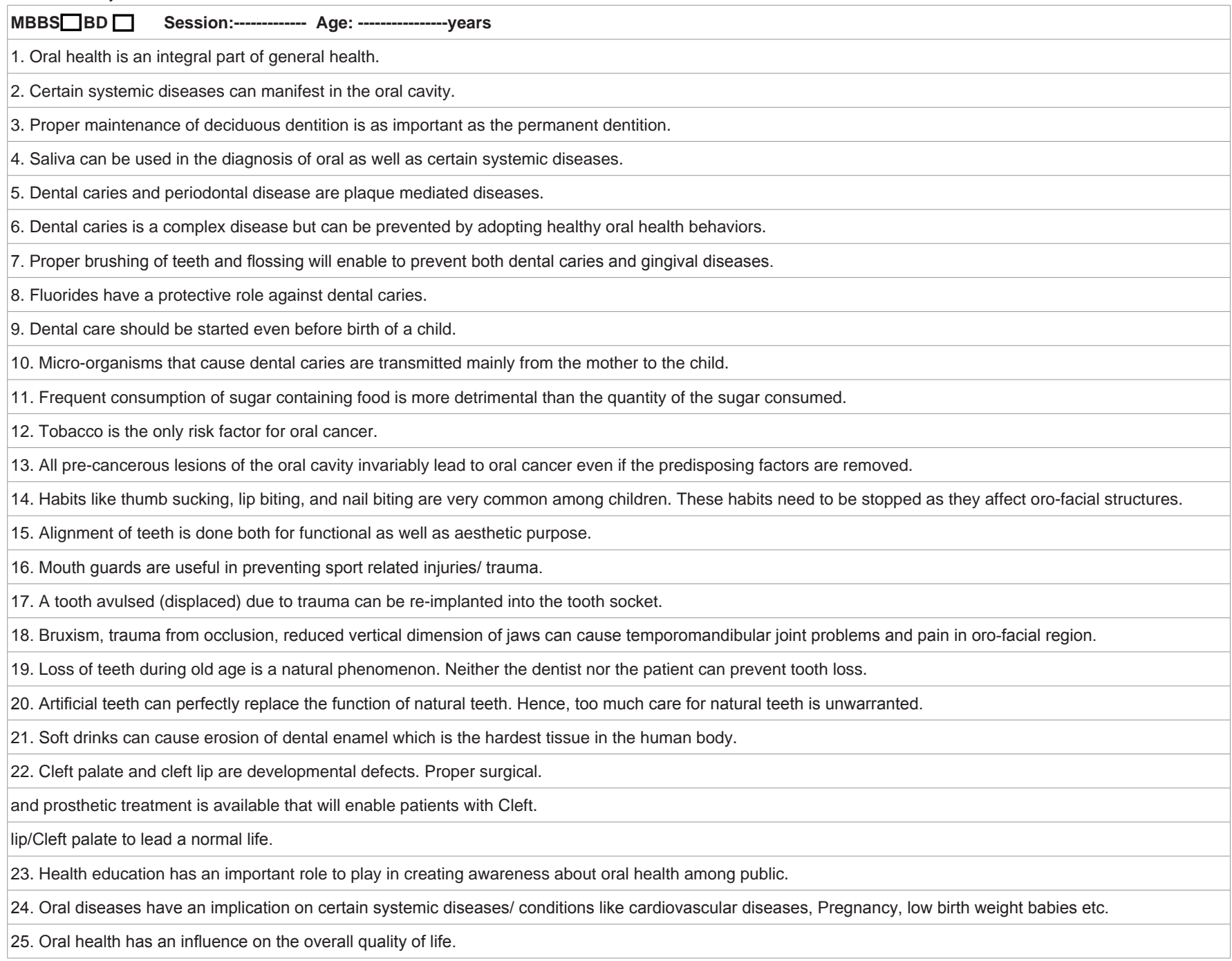

and awareness of medical professionals regarding oral health and the nature of oral diseases have an essential role in comprehensive patient care. Very few studies have assessed oral health knowledge of 'physicians' and/or medical students in the Kingdom of Saudi Arabia [15]. Therefore, this study was undertaken to observe the knowledge about the common oral and dental problems, their etiology and relation to general health among medical students as compared to dental students.

\section{Methods}

This cross-sectional questionnaire based study was conducted on undergraduate medical and dental students of King Faisal University, Saudi Arabia, in September 2019. Study subjects included medical students from $1^{\text {st }}$ to $5^{\text {th }}$ years of MBBS and dental students from $1^{\text {st }}$ to $4^{\text {th }}$ years of BDS. The institutional review board of the College of Dentistry, King Faisal University, approved the study vide letter \#CoD/R/0013/2019 (04/04/19) for compliance of the ethical and research guidelines. Informed consent was obtained from the study participants after explaining them the objectives of the study and methods involved. It was explicitly stated that their participation would be voluntary. Respondents were asked to fill the questionnaires in the classroom after obtaining permission from the respective Deans and course instructors of the individual sessions. One of the investigators was present to clarify any doubts while the students filled the questionnaire. Responses were collected from those students who were available on the day of survey. Questionnaires were distributed to $200 \mathrm{MBBS}$ students and 88 BDS students. The response rate was $87 \%$ for medical students and $100 \%$ for dental students. Questionnaires were collected and screened by one of the investigators (SS) for completeness. All the questionnaires with more than three unanswered questions or with multiple answers were excluded from the analysis.

A structured and close-ended questionnaire was used to assess the knowledge level of the respondents (Table 1). The questionnaire was utilized in a similar study conducted by Sujatha et al. [11]. It was pretested and validated for the present study. The questionnaire included four questions regarding age, gender, the stream of study and study year. Twenty-five questions were posed to assess knowledge related to common oral diseases or conditions, their etiology and relation to systemic conditions, dental treatment and related dietary factors. The respondents had to choose only one of the options from 'Agree', 'Disagree', and 'Don't know'. The questions were so designed 
Table 2: Demographic Characteristics of Study Participants.

\begin{tabular}{|c|c|c|c|c|}
\hline Characteristics & $\begin{array}{l}\text { Medical Students } \\
n=171(66 \%)\end{array}$ & 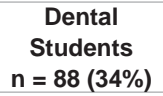 & $\begin{array}{c}\text { Total } \\
n=259 \\
-100 \%\end{array}$ & p-value \\
\hline \multicolumn{5}{|l|}{ Age (years) } \\
\hline Mean $\pm S D$ & $21.25 \pm 1.73$ & $20.58 \pm 1.16$ & $21.02 \pm 1.59$ & $0.001^{*}$ \\
\hline$\leq 21$ years & $106(62)$ & $66(75)$ & $172(66)$ & $0.038^{* *}$ \\
\hline$>21$ years & $65(38)$ & $22(25)$ & $87(34)$ & \\
\hline \multicolumn{5}{|l|}{ Sex } \\
\hline Male & $129(50)$ & $88(34)$ & 217 (84) & $0.001^{* *}$ \\
\hline Female & $42(16)$ & 0 & $42(16)$ & \\
\hline \multicolumn{5}{|l|}{ Year of Study } \\
\hline $1^{\text {st }}$ year & $64(25)$ & $23(9)$ & $87(34)$ & $0.001^{* *}$ \\
\hline $2^{\text {nd }}$ year & $19(7)$ & $19(7)$ & $38(15)$ & \\
\hline $3^{\text {rd }}$ year & $25(10)$ & $25(10)$ & $50(19)$ & \\
\hline $4^{\text {th }}$ year & $21(8)$ & $21(8)$ & $42(16)$ & \\
\hline $5^{\text {th }}$ year & $42(16)$ & 0 & $42(16)$ & \\
\hline
\end{tabular}

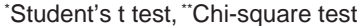

that 'Agree' happens to be the correct answer for all the items, except for questions \#10,12,13 and 20. To calculate the total knowledge level of the respondents, the correct answer carries 2 points, and the other two possibilities carry one and zero points. The knowledge of the students was calculated by adding the scores of all items and expressing it in percentage. Knowledge of the respondents was graded as 'good' (score $>70 \%)$, 'fair' (50-69\%), and 'poor' $(<50 \%)$.

Data were entered into SPSS (version 20.0, Chicago, IL, USA) statistical analysis. Descriptive statistics (frequencies, percentages and mean) were used to summarise the data. Chi-square test was used to test the significant difference in proportions. Kruskal-Wallis test and Mann Whitney $U$ test were used to test the difference in oral health awareness scores among different categories of study subjects. A probability level of less than 0.05 was considered statistically significant.

\section{Results}

Out of 262 questionnaires collected from the respondents, a total of 259 questionnaires were completely answered and considered for statistical analysis. This comprised of questionnaires answered by 171 medical and 88 dental students. Table 2 shows the demographic details of the respondents. The mean age of medical students, who participated in the study was $21.25 \pm 1.73$ years, and that of dental students was $20.58 \pm 1.16$ years. Mean age and proportion of students above the mean age were lower for dental students as compared to medical students. Out of 171 medical students, 129 were males and 42 were females, whereas all the dental students were males.

Medical students showed a 'good' level of knowledge on 16 (64\%) items, whereas dental students showed a 'good' level of knowledge on 18 items $(72 \%)$. The difference was statistically significant $(p=0.02)$ as indicated by Chi-square test. Male students across both the streams displayed a good level of knowledge on 17 items. Female students were present only in Medical College. They displayed a 'good' level of knowledge on 11 items. The difference shown was statistically significant $(\mathrm{p}=0.001)$ as indicated by Chi-square test (Figure 1).

Figure 2 shows the level of knowledge of the medical and dental students, as reflected by the percentage scores obtained by them to the 25 item questionnaire. Dental students scored marginally better than medical students for 14 items. Medical students scored better than dental students for items 9 and 10 . However, the difference in mean scores was not statistically significant between medical and dental

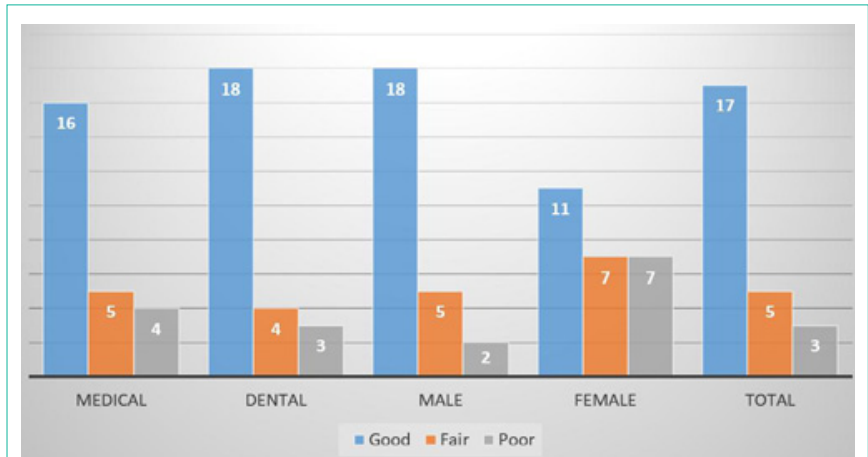

Figure 1: Study Participants' distribution (n) by "Good, Fair and Poor" Category of knowledge on the questionnaire items.

students ( $\mathrm{p}=0.21$, Mann Whitney $\mathrm{U}$ test). Mean score of medical students was $76.16 \%$ and that of dental students was $78.08 \%$. All the students from both medical and dental streams acknowledged that "Oral health is an integral part of general health" (Item 1). Almost all medical and dental students agreed that "Certain systemic diseases are manifested in the oral cavity" (Item 2). Almost all of the dental students (98\%) responded positively for the item "Health education has an important role to play in creating awareness about oral health among public" (Item 23), where as the percentage of medical students who responded positively for the same item was $93 \%$. More than $50 \%$ of the medical and dental students provided wrong answers for items 9, 10, 13, 19 and 20. Students from both the streams displayed very poor knowledge on vertical transmission of micro organisms from mother to child. Only $33 \%$ of the medical and $25 \%$ of the dental students answered correctly for the item "Micro organisms that cause dental caries are transmitted mainly from the mother to the child" (Item 10). Percentage of medical and dental students who proided correct answers for the item "Dental care should be started even before birth of a child" was $44 \%$ and $32 \%$ respectively (Item 9). Percentage of the medical and dental students who provided correct answer for the item "Loss of teeth during old age is a natural phenomenon. Neither the dentist nor the patient can prevent tooth loss" (Item 19) was 50\% and $52 \%$ respectively.

Responses were analysed to see the difference in knowledge levels between males and females. Figure 3 shows comparative scores obtained for male and female students irrespective of the stream of study. Mean score of male students to all the questions was $80.68 \%$ and that of female students was $66.96 \%$; There was a statistically significant difference ( $\mathrm{p}=0.001$, Mann Whitney $\mathrm{U}$ test). Male students scored better than female students for most of the questions. The proportion of male students who gave correct answer was more than 30 percentage points higher than that of female students for the items $12,15,16,17,18$ and 20. Percentage of the male and female students who provided correct answer for the item "Alignment of teeth is done both for functional as well as aesthetic purpose" (Item 15) was $91 \%$ and $62 \%$ respectively. For the item "Mouth guards are useful to prevent sport related injuries/ trauma" (Item 16), 72\% of male students and $35 \%$ of female students gave correct answer. On the contrary, Female students scored exceptionally better than male students (64\% and 35\% respectively) for the item "Dental care should be started even before the birth of a child" (Item 9). 


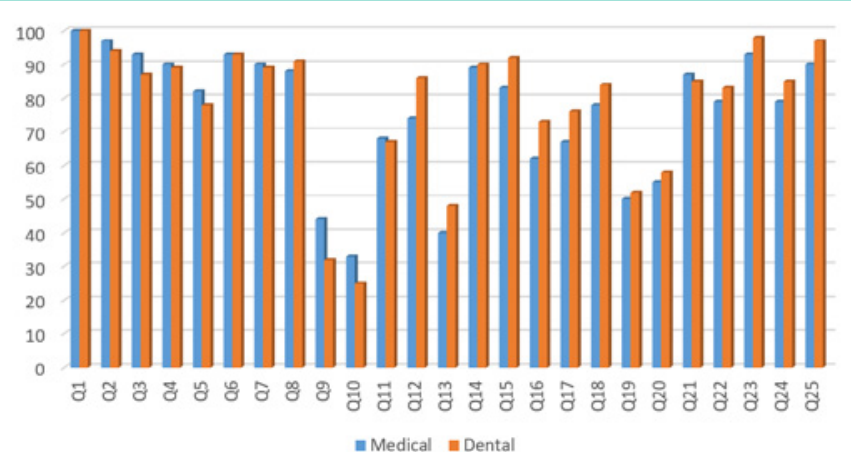

Figure 2: Study Participants' knowledge (\%) by stream of study.

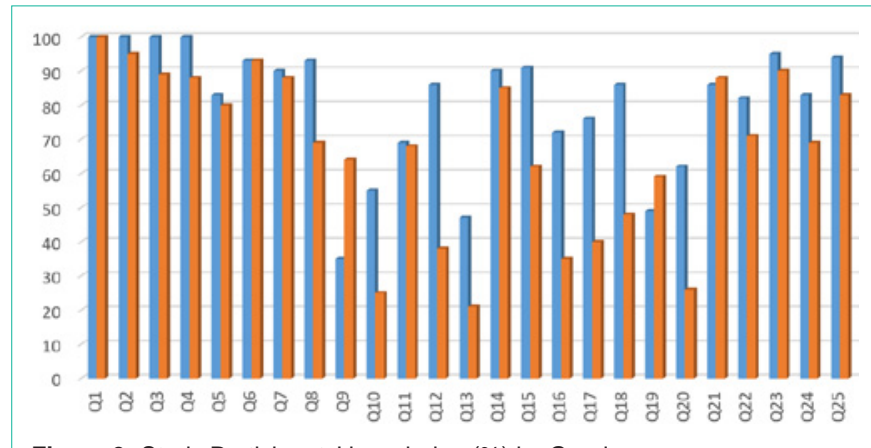

Figure 3: Study Participants' knowledge (\%) by Gender.

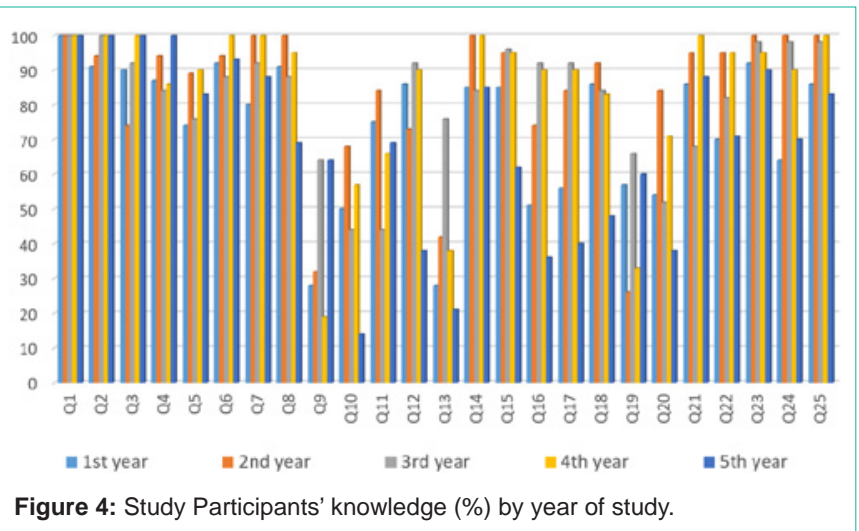

Responses were analysed about the academic year of the students to see if the knowledge levels of medical and dental students vary between students of different academic years. Figure 4 shows comparative scores obtained by students belonging to different academic years. Students belonged to years 2, 3 and 4 displayed better knowledge compared to those from years 1 and 5. Students from any particular year did not seem to be having consistently better knowledge than the other years across all the items. Mean scores obtained by the students belonging to $1^{\text {st }}, 2^{\text {nd }}, 3^{\text {rd }}, 4^{\text {th }}$ and $5^{\text {th }}$ year was $73.76 \%, 83.56 \%, 82.00 \%, 83.32 \%$ and $68.4 \%$ respectively. The difference was statistically significant ( $\mathrm{p}=0.001$, Kruskal- Wallis test).

\section{Discussion}

Being future health professionals, medical and dental students are expected to possess adequate knowledge in identifying and managing different oral conditions [1]. Studies have reported that poor oral health knowledge of medical students as a direct consequence of under-exposure to dental education in most of the undergraduate medical curricula [16,17]. Medical students, who received some form of formal training on oral health, rated the course as highly informative and advocated for further integration of oral health into the medical curriculum [18]. Nwhator et al. [13] demonstrated a positive association between exposure to some form of formal dental education in undergraduate studies and oral health knowledge.

This study assessed medical students' knowledge about oral health and compared it with that of dental students. Dental students scored better than medical students for the majority of the questions. Mean knowledge score was significantly higher among males than female students. Students from any particular year did not seem to be having consistently better knowledge than the other years across all the items.

The results of this study are corroborating and coherent with other local studies [19-21]. $4^{\text {th }}, 5^{\text {th }}$, and $6^{\text {th }}$-year undergraduate medical students were assessed by Kujan and Abuderman [19] Fifty-three per cent of respondents provided correct answers to all questions related to oral cancer (mean score 57.8\%), that is higher in our study (78\%) and no significant association was found with either gender $(\mathrm{p}=0.37)$ or academic year $(\mathrm{p}=0.23)$ concordant with our investigation. Togoo et al. [21] observed $83 \%$ of Saudi dentists identified poor oral hygiene as a significant reason for the high prevalence of caries as compared to $89 \%$ dental students of our study. A Saudi Arabian study [20] reported variable level of knowledge among health professionals. Less than $37 \%$ of the subjects had a correct understanding of the meaning of plaque, the role of plaque in initiating gum disease and methods of preventing gingivitis. In the present study, $82 \%$ of the medical students could provide the correct answer to the question of plaque. More than $65 \%$ of health professionals displayed the right knowledge about the role of dental plaque in causing dental caries and the consequences of gingival bleeding and dental caries on dental aesthetics. Oral health knowledge was found to be good among health professionals, with more than $85 \%$ of them displaying the correct understanding of how sweets and soft drinks affect dental health, relation between general health and oral health and the importance of treatment of toothache. Alyousaf et al. [15] reported that $90 \%$ of physicians considered their role as necessary in counselling/referring patients with oral health. $70 \%$ of medical students graded their knowledge as poor for perceived importance of medical problems in dentistry.

In comparison to international studies, Malaysian undergraduate dental students also showed a significantly higher level of knowledge (93.9\%) as compared to medical students (79.8\%) with respect to examine oral mucosa and give advice for oral cancer [22]. Whereas in a study by Dayakar et al. [23] only $18 \%$ of medical students were aware of the common cause of bleeding gums, $86 \%$ knew that poor oral hygiene causes bad breath, $94 \%$ considered that bad oral health effects general health. A study conducted on Kuwaiti university health sciences students showed that $29.5 \%$ were not aware of any measures to prevent gum bleeding [24]. In an African study, $42 \%$ considered dental problems in medicine as very important [10]. In a study from Nigeria, 50\% of medical doctors strongly agreed that there is an association between oral diseases and systemic conditions. However, $18.8 \%$ did not consider any association between oral health 
and hypertension or low birth weight babies [25]. Another study among Nigerian non-dental resident doctors revealed that only 5.6\% had good knowledge about dental specialties [26] comparable to our study where medical students showed $64 \%$ knowledge.

In another study [6] it was reported that $54 \%$ of physicians believed that tooth and gums problem could affect the outcomes of pregnancy, and in another study [7] both dentists and physicians believed an association between diabetes and periodontal disease as compared to $79 \%$ medical students of our research. In a study from Pakistan, 76\% of the respondents opined that mouth was not the only source of bad breath and $49 \%$ believed that chronic periodontitis could be a risk factor for Coronary Heart Disease (CHD). About 30\% of the study participants believed that pregnancy-related periodontitis could lead to low birth weight of the newborn; $54 \%$ of them believed that there exists a positive association between periodontitis and diabetes mellitus; and $79 \%$ felt that smoking negatively affects periodontal health [27].

Quijano et al. [4] noted that 34\% of the medical trainees could correctly answer all five general questions regarding bleeding gums, poor oral health and periodontal disease; $82 \%$ revealed that they never asked their patients if they were diagnosed with periodontal disease. In other studies, almost all physicians (95\%) opined that it was necessary for a physician to have adequate knowledge about oral health care and 78\% admitted that physicians have limited knowledge [9]. Participants displayed a moderate level of knowledge about the signs and symptoms of gum disease, dental caries and management of poor oral hygiene; etiology of the facial swelling and mouth ulcers; the conditions that needed to be referred to a dentist and the oral manifestations of systemic diseases [28]. $75 \%$ of medical undergraduates knew that periodontal disease increases the risk of cardiovascular disease. $77 \%$ were aware of systemic complications due to untreated dental conditions [29]. A study in Turkey reported $90.8 \%$ of doctors believed a relationship between PD and systemic health [30]. In the present study, $79 \%$ of medical and $85 \%$ of dental students believed that oral diseases have implications on systemic diseases.

Sujatha et al. [11] reported that the proportion of the undergraduate students with good, fair and poor levels of oral health knowledge was $25 \%, 38 \%$ and $37 \%$ respectively. Final year undergraduate medical students showed better oral health knowledge (40\%) when compared to second (13\%) and third-year students (23\%). In the present study, students of any particular year did not exhibit superior knowledge compared to other years. $80 \%$ of medical and $96 \%$ of dental students considered maintaining oral health as important as general health. A significant proportion of medical students (96\%) displayed poor knowledge of the role of fluorides in dental hygiene. Whereas, $88 \%$ of medical students and $91 \%$ of dental students were aware of the same in our study. One study [17] reported that $36 \%$ of medical students have never heard of the term flossing. In the present study, $90 \%$ of medical students were aware of flossing, and they believed that regular flossing plays a vital role in preventing dental caries and gum diseases.

The overall level of awareness and knowledge about oral health among medical students is found to be good in our study. However, more than half of the medical and dental students were found to be having poor knowledge in three items: (1) "Dental care should be started even before birth of a child", (2) "Micro-organisms that cause dental caries are transmitted mainly from mother to child" and (3) "All pre-cancerous lesions of the oral cavity invariably lead to oral cancer even if the predisposing factors are removed". These concepts have an essential role in the prevention of the disease and hence the medical, as well as dental graduates, needs to have knowledge on these items. Curtis et al. observed that a basic understanding of dentistry by medical practitioners and a basic knowledge of medicine by dental practitioners can improve communication between the professions [31].

The clinical implication of our study is that future physicians should be aware of necessary oral health assessments and recommend oral health examinations during their practice. The marginal difference between the knowledge levels of medical and dental students probably highlights the potential benefits of introducing basic oral health issues in the undergraduate medical curriculum to enhance the effectiveness of current oral health education attempts.

\section{Conclusion}

This study has demonstrated a moderate to good level of oral health knowledge among the study participants. Dental students and men displayed somewhat better knowledge levels compared to medical students and women, respectively. This study has also identified gaps in the knowledge, specific to oral health and common oral diseases, among medical and dental students. Study limitation may the small sample size.

Clinical Significance: This study highlights the importance of scientific oral health knowledge for the future health care professionals. Objective is to draw attention towards incorporation of preventive oral health sciences in medical curriculum at undergraduate level.

\section{References}

1. Yao K, Yao Y, Shen X, Lu C, Guo Q. Assessment of the oral health behavior, knowledge and status among dental and medical undergraduate students: A cross-sectional study. BMC Oral Health. 2019; 19: 1-8.

2. Morgan R, Tsang J, Harrington N, Fook L. Survey of hospital doctors' attitudes and knowledge of oral conditions in older patients. Postgrad Med J. $2001 ; 77: 392-394$

3. Yuen HK, Onicescu G, Hill EG, Jenkins C. A survey of oral health education provided by certified diabetes educators. Diabetes Res Clin Pract. 2010; 88: 48-55.

4. Quijano A, Shah AJ, Schwarcz AI, Lalla E, Ostfeld RJ. Knowledge and Orientations of Internal Medicine Trainees Toward Periodontal Disease. J Periodontol. 2010; 81: 359-363.

5. Azodo C, Ehizele A, Adeghe $\mathrm{H}$, Ehigiator O. Nigerian clinical level medical students' knowledge of dental specialty. Ann Med Health Sci Res. 2012; 2: 157.

6. Al-Habashneh R, Aljundi SH, Alwaeli HA. Survey of medical doctors' attitudes and knowledge of the association between oral health and pregnancy outcomes. Int J Dent Hyg. 2008; 6: 214-220.

7. Al-Khabbaz AK, Al-Shammari KF, Al-Saleh NA. Knowledge about the Association between Periodontal Diseases and Diabetes Mellitus: Contrasting Dentists and Physicians. J Periodontol. 2011; 82: 360-366.

8. Asaad F, Al-Maflehie N, Alelyan B, Asaad L, Alrumaih W, Alassad F, et al. Knowledge and orientations of medical interns toward periodontal disease in Saudi Arabia. Saudi J Oral Sci. 2014; 1: 98-104.

9. Rabiei S, Mohebbi SZ, Patja K, Virtanen Jl. Physicians knowledge of and 
adherence to improving oral health. BMC Public Health. 2012; 12.

10. Gill Y, Scully C. Attitudes and awareness of final-year predoctoral dental and medical students to medical problems in dentistry. J Dent Educ. 2006; 70 991-995

11. Sujatha B, Yavagal P, Gomez MS. Assessment of oral health awareness among undergraduate Medical Students in Davangere city: A cross-sectional survey. J Indian Assoc Public Health Dent. 2014; 12: 43-46.

12. Balaban R, Aguiar CM, Da Silva Araújo AC, Dias Filho EBR. Knowledge of paediatricians regarding child oral health. Int J Paediatr Dent. 2012; 22: 286 291.

13. Nwhator SO, Olojede CO, ljarogbe O, Agbaje MO. Self-Assessed Denta Health Knowledge of Nigerian Doctors. East Afr Med J. 2013; 90: 147-155.

14. Raoof M, Vakilian A, Kakoei S, Manochehrifar H, Mohammadalizadeh S Should medical students be educated about dental trauma emergency management? A study of physicians and dentists in Kerman province, Iran. J Dent Educ. 2013; 77: 494-501.

15. Alyousef Y, Damiano P, Weber-Gasparoni K, Qian F, Murph J, Nothwehr F. Medical students' child oral-health-related knowledge, practices and attitudes. Eur J Dent Educ. 2013; 17: 218-224.

16. Kumari Nr, Sheela S, Sarada P. Knowledge and attitude on infant oral health among graduating medical students in Kerala. J Indian Soc Pedod Prev Dent. 2006; 24: 173-176.

17. Sargod SS, Usman S, Bhat SS. Oral Health Knowledge and Behavior of Clinical Medical, Dental and Paramedical Students in Mangalore. J Oral Health Community Dent. 2007; 1: 46-48.

18. Skelton J, Smith TA, Betz WT, Heaton LJ, Lillich TT. Improving the oral health knowledge of osteopathic medical students. J Dent Educ. 2002; 66: 12891296.

19. Kujan O, Abuderman A, Azzegahiby S, Alenzi FQ, Idrees M. Assessing oral cancer knowledge among Saudi medical undergraduates. J Cancer Educ. 2013; 28: 717-721.

20. Baseer MA, Alenazy MS, Alasqah M, Algabbani M, Mehkari A. Oral health knowledge, attitude and practices among health professionals in King Fahad Medical City, Riyadh. Dent Res J (Isfahan). 2012; 9: 386-392.
21. Togoo RA, Al-Rafee MA, Kandyala R, Luqam M, Al-Bulowey MA. Dentists' opinion and knowledge about preventive dental care in Saudi Arabia: a nationwide cross-sectional study. J Contemp Dent Pract. 2012; 13: 261-265.

22. Awan K, Khang T, Yee T, Zain R. Assessing oral cancer knowledge and awareness among Malaysian dental and medical students. J Cancer Res Ther. 2014; 10: 903-907.

23. Dayakar MM, Kumar J, Pai GP, Shivananda H, Rekha R. A survey about awareness of periodontal health among the students of professional colleges in Dakshina Kannada District. J Indian Soc Periodontol. 2016; 20: 67-71.

24. Al-Hussaini R, Al-Kandari M, Hamadi T, Al-Mutawa A, Honkala S, Memon A. Dental Health Knowledge, Attitudes and Behaviour among Students at the Kuwait University Health Sciences Centre. Med Princ Pract. 2003; 12 : 260-265.

25. Opeodu O, Fasunla A, Ogunrinde T. An assessment of medical doctors' perception of possible interrelationship between oral and general health. Eur J Gen Dent. 2014; 3: 120-124.

26. Azado CC, Ehigiator O, Ehizele AO, Ololo O. Medical Doctors' Knowledge of Dental Specialty: Implication for Referral. Sarat Naucno-medicinskij Zurnal. 2010; 6: 140-143.

27. Shah N, Sundaram KR. Impact of Socio-Demographic Variables, Oral Hygiene Practices, Oral Habits and Diet on Dental Caries Experience of Indian Elderly: A Community-Based Study. J khyber Coll Dent. 2013; 4: 3437.

28. Sarumathi T, Saravanakumar B, Datta M, Nagarathnam T. Awareness and knowledge of common oral diseases among primary care physicians. J Clin Diagnostic Res. 2013; 7: 768-771.

29. Ingle NA, Srinidhi S, Chaly PE, Reddy C. Dental Awareness and Attitudes among Medical Practitioners in Chennai. J Oral Health Community Dent. 2011; 5: 73-78.

30. Tasdemir Z, Alkan BA. Knowledge of medical doctors in Turkey about the relationship between periodontal disease and systemic health. Braz Oral Res. 2015; 29: 55.

31. Curtis JW, Garrison RS, Camp MG. Dentistry in medical education: results of a comprehensive survey. J Med Educ. 1985; 60: 16-20. 